\title{
Silver colloidal nanoparticle stability: influence on Candida biofilms formed on denture acrylic
}

\author{
Douglas Roberto Monteiro 1,*, Aline Satie Takamiya1, \\ Leonardo Perina Feresin ${ }^{1}$, Luiz Fernando Gorup², \\ Emerson Rodrigues de Camargo ${ }^{2}$, Alberto Carlos Botazzo Dellbem', \\ Mariana Henriques ${ }^{3}$ and Debora Barros Barbosa ${ }^{4}$
}

${ }^{1}$ Department of Pediatric Dentistry and Public Health, Araçatuba Dental School, Universidade Estadual Paulista, Araçatuba/São Paulo, Brazil, ${ }^{2}$ LIEC-Department of Chemistry, Federal University of São Carlos, São Carlos/São Paulo, Brazil, ${ }^{3}$ Institute for Biotechnology and Bioengineering, Department of Biological Engineering, University of Minho, Braga, Portugal and ${ }^{4}$ Department of Dental Materials and Prosthodontics, Araçatuba Dental School, Universidade Estadual Paulista, Araçatuba/São Paulo, Brazil

\footnotetext{
*To whom correspondence should be addressed. Douglas Roberto Monteiro, Department of Pediatric Dentistry and Public Health, Araçatuba Dental School, Universidade Estadual Paulista, 16015-050 Araçatuba/São Paulo, Brazil. Tel: +55 18 36363284; Fax: +55 18 36363245; E-mail: douglasrmonteiro@hotmail.com
}

Received 3 March 2014; Revised 4 December 2013; Accepted 8 March 2014

\begin{abstract}
Our aim in this study was to evaluate how the chemical stability of silver nanoparticles (SNs) influences their efficacy against Candida albicans and C. glabrata biofilms. Several parameters of $\mathrm{SN}$ stability were tested, namely, temperature $\left(50^{\circ} \mathrm{C}, 70^{\circ} \mathrm{C}\right.$, and $\left.100^{\circ} \mathrm{C}\right), \mathrm{pH}$ (5.0 and 9.0), and time of contact ( $5 \mathrm{~h}$ and $24 \mathrm{~h}$ ) with biofilms. The control was defined as SNs without temperature treatment, $\mathrm{pH} \mathrm{7,} \mathrm{and} 24 \mathrm{~h}$ of contact. These colloidal suspensions at $54 \mathrm{mg} / \mathrm{L}$ were used to treat mature Candida biofilms (48 h) formed on acrylic. Their efficacy was determined by total biomass and colony-forming unit quantification. Data were analyzed using analysis of variance and the Bonferroni post hoc test $(\alpha=0.05)$. The temperature and $\mathrm{pH}$ variations of SNs did not affect their efficacy against the viable cells of Candida biofilms $(P>0.05)$. Moreover, the treatment periods were not decisive in terms of the susceptibility of Candida biofilms to SNs. These findings provide an important advantage of SNs that may be useful in the treatment of Candida-associated denture stomatitis.
\end{abstract}

Key words: silver nanoparticles, chemical stability, biofilms, Candida albicans, Candida glabrata.

\section{Introduction}

Candida-associated denture stomatitis is frequent in elderly people, especially those who wear complete dentures, and is one of the most common forms of oral candidia- sis $[1,2]$. Even though Candida albicans is strongly associated with the development of denture stomatitis, nonC. albicans Candida species, such as C. glabrata, may also contribute to this pathological condition $[3,4]$. Candida species form biofilms on acrylic denture surfaces that 
are characterized by networks of yeasts, pseudohyphae, and hyphae surrounded by an extracellular matrix [5] and embedded mainly into irregularities of acrylic surfaces [6]. Unlike C. albicans, C. glabrata do not form hyphae [7].

Although antifungal suspensions that are based on nystatin, amphotericin B, miconazole, and fluconazole have been widely used to treat denture stomatitis [8,9], Candida infections are frequently recalcitrant to conventional treatments [1,10-12]. Indeed, established Candida biofilms are more resistant to antimicrobial agents than their planktonic counterparts $[13,14]$. This serious clinical impact of increased resistance to conventional antifungal therapy has strengthened the search for alternative strategies that could contribute significantly to the prevention and destruction of Candida biofilm formation. For this purpose, silver nanoparticles ( $\mathrm{SNs}$ ) are recognized as a new class of antimicrobial agents [15] because of their effective antimicrobial ability. SNs have a large surface area and high reactivity compared with microparticles [16]. In dentistry, these nanoparticles have been incorporated into dental adhesives $[17,18]$ and resin composites [19] in order to inhibit dental caries and into denture base acrylic resin [20] in order to prevent stomatitis.

The mechanisms of killing microorganisms of SNs are multifactorial $[15,16,21-23]$, and it is believed that these mechanisms are similar to those of silver ions (SIs) [21,24]. In general, $\mathrm{SNs}$ bind to sulfur-containing proteins in biological molecules, resulting in defects in the microbial cell membrane and loss of intracellular contents; inhibition of respiratory chain enzymes; and binding to phosphoruscontaining compounds such as DNA, preventing cell reproduction [15,16,21-23]. The targets of action of SNs have been relatively well described in complex studies [21-23,25].

Recently, it was demonstrated that SNs affected the extracellular matrix composition and structure of Candida biofilms [26] and exhibited synergistic antibiofilm activity when combined with either nystatin or chlorhexidine digluconate [27]. In light of the therapeutic potential of SNs, one essential aspect that remains to be established is the impact of the chemical stability of SNs on their efficacy against Candida biofilms. Variables such as temperature, ionic strength, and nature of the immersion medium (composition and $\mathrm{pH}$ ) may influence the size, rate of dissolution, aggregation, and stability of SNs [28-30]. The loss of chemical stability could cause aggregation of SNs and reduction of their effectiveness against biofilms. Thus, our aim in this study was to evaluate how the chemical stability of silver nanoparticles (SNs) influences their efficacy against Candida albicans and C. glabrata biofilms.

\section{Materials and methods}

\section{Synthesis and characterization of silver colloidal nanoparticles}

SNs were synthesized in accordance with a previously described procedure [28]. Briefly, $5.0 \times 10^{-3} \mathrm{~mol} / \mathrm{l}$ silver nitrate (Merck KGaA, Darmstadt, Germany) was reduced by the addition of $0.3 \mathrm{~mol} / \mathrm{l}$ sodium citrate (Merck KGaA). The solution turned amber yellow and a colloidal suspension was formed. Then, the silver colloids were stabilized by the addition of $1.4 \mathrm{~mol} / \mathrm{l}$ ammonia (Merck KGaA). SN suspensions were characterized by ultraviolet/visible (UV/vis) spectroscopy (Shimadzu MultSpec-1501 spectrophotometer; Shimadzu Corporation, Tokyo, Japan) and by transmission electron microscopy (FEG-VP Supra 35 electron microscope; Carl Zeiss, Jena, Germany). The typical absorption spectrum of SNs, centered at $430 \mathrm{~nm}$, was located in the UV/vis spectrum; electron micrograph images displayed spherical SNs with an average particle size of $5 \mathrm{~nm}$ $[14,31]$. The $\mathrm{SN}$ concentration of $54 \mathrm{mg} / \mathrm{l}$ used in this study was based on its efficacy against Candida biofilms reported in previous studies [14,26,31].

\section{Chemical stability of SNs through temperature and $\mathrm{pH}$ variations}

Chemical stability assays were carried out at room temperature based on the method of Ellis et al. [32], with some modifications. For the temperature stability assay, stock suspensions of $\mathrm{SNs}$ in glass tubes were placed in a water bath at $50^{\circ} \mathrm{C}(\mathrm{SN}-50), 70^{\circ} \mathrm{C}(\mathrm{SN}-70)$, and $100^{\circ} \mathrm{C}(\mathrm{SN}-100)$ for $30 \mathrm{~min}$. The resultant $\mathrm{SN}$ colloidal suspensions were also characterized by UV/vis spectroscopy as cited above. Later, SN suspensions (preheated) were diluted in Roswell Park Memorial Institute (RPMI) 1640 medium (Sigma-Aldrich, St. Louis, MO, USA) to achieve a silver concentration of $54 \mathrm{mg} / \mathrm{l}$.

For the $\mathrm{pH}$ stability assay, the $\mathrm{pH}$ of the $\mathrm{SN}$ suspensions at $54 \mathrm{mg} / \mathrm{l}$ (diluted in RPMI 1640 medium) was adjusted to $\mathrm{pH} 5.0(\mathrm{SN}-\mathrm{pH}$ 5) or $\mathrm{pH} 9.0(\mathrm{SN}-\mathrm{pH}$ 9) using solutions of $1 \mathrm{M}$ hydrochloric acid and $1 \mathrm{M}$ sodium hydroxide, respectively. After $2 \mathrm{~h}$ at room temperature, the $\mathrm{pH}$ was readjusted to $\mathrm{pH}$ 7.0.

\section{Substrate preparation}

The substrate used for biofilm formation was denture acrylic resin. For standardization of acrylic resin specimens, a stainless steel matrix with internal molds was fixed with wax (Wilson, São Paulo, Brazil) on a glass plate with a rough surface (to mimic the roughness of the palate) 
and invested in metallic flask with type III dental stone (Herodent, Petrópolis, Brazil). After the dental stone set, the flask halves were separated, the wax was removed, and the matrix molds and glass plate were cleaned. The denture resin (QC20; Dentsply Ind. e Com. Ltd., Petrópolis, Brazil) was manipulated, packed, pressed into the matrix molds, and polymerized according to the manufacturer's recommendations. After bench cooling at room temperature, the specimens $(10 \times 10 \times 3 \mathrm{~mm})$ were deflasked, and the excess resin was removed with a bur (Maxi-Cut; Maillefer SA, Ballaigues, Switzerland). The acrylic specimens were then rinsed with deionized water, dried at room temperature, and sterilized [5].

\section{Artificial saliva medium}

Artificial saliva (AS; pH 6.8) was the medium used for biofilm formation [33]. Its composition was as follows: $2 \mathrm{~g}$ of yeast extract (Sigma-Aldrich), $5 \mathrm{~g}$ of peptone (SigmaAldrich), $2 \mathrm{~g}$ of glucose (Synth, Diadema, Brazil), $1 \mathrm{~g}$ of mucin (Sigma-Aldrich), $0.35 \mathrm{~g}$ of sodium chloride (Merck $\mathrm{KGaA}$ ), $0.2 \mathrm{~g}$ of calcium chloride (Sigma-Aldrich), and $0.2 \mathrm{~g}$ of potassium chloride (Merck KGaA) per 11 of deionized water.

\section{Yeast strains and growth conditions}

Two strains of C. albicans and C. glabrata were tested. In addition to the reference C. albicans (American Type Culture Collection [ATCC] 10231) and C. glabrata (ATCC 90030), two Candida oral clinical isolates were used, namely, C. albicans 324LA/94 (obtained from the culture collection of Cardiff Dental School, Cardiff, UK) and C. glabrata D1 (obtained from the Biofilm Group of the Centre of Biological Engineering, University of Minho, Braga, Portugal).

All yeast strains were grown aerobically on Sabouraud glucose agar medium (SGA; Difco, Le Pont de Claix, France) at $37^{\circ} \mathrm{C}$ for $24 \mathrm{~h}$. A loopful of the Candida colonies from SGA plates was inoculated into Sabouraud glucose broth (SGB; Difco) medium and incubated at $37^{\circ} \mathrm{C}$ for 20-24 h under agitation (120 rpm). After being harvested by centrifugation $\left(6500 \mathrm{~g}\right.$ for $5 \mathrm{~min}$ at $15^{\circ} \mathrm{C}$ ), cell pellets were washed twice in phosphate-buffered saline (PBS; pH 7, $0.1 \mathrm{M}$ ) and the cellular density adjusted to $1 \times 10^{7}$ cells $/ \mathrm{ml}$ in AS, using a Neubauer hemocytometer. These Candida cell suspensions were used in the subsequent biofilm formation assays.

\section{Biofilm formation and treatment with $\mathrm{SNs}$}

Candida biofilms were formed on acrylic resin specimens according to Silva et al. [5]. Briefly, acrylic specimens were placed in 24-well microtiter plates (Costar, Tewksbury, USA) and $1 \mathrm{ml}$ of the standardized Candida cell suspension $\left(1 \times 10^{7}\right.$ cells $/ \mathrm{ml}$ in AS) was added to each well and incubated at $37^{\circ} \mathrm{C}$ for $48 \mathrm{~h}$ under agitation $(120 \mathrm{rpm})$. After $24 \mathrm{~h}, 500 \mu \mathrm{l}$ of AS was removed and an equal volume of fresh AS was added. Following Candida biofilm formation $(48 \mathrm{~h})$, AS was removed and the acrylic specimens were washed once with $1 \mathrm{ml}$ of PBS to remove nonadherent cells. Then, $1 \mathrm{ml}$ of $54 \mathrm{mg} / \mathrm{l} \mathrm{SNs}$ (with temperature and $\mathrm{pH}$ variations, as previously described) diluted in RPMI 1640 medium was added to the preformed Candida biofilms and incubated at $37^{\circ} \mathrm{C}$ for $24 \mathrm{~h}$ under agitation $(120 \mathrm{rpm})$. For positive and negative controls, Candida biofilms were preformed on acrylic specimens and then incubated with $54 \mathrm{mg} / \mathrm{l}$ of SNs without temperature and $\mathrm{pH}$ variations and with RPMI 1640 medium without SNs, respectively.

To evaluate the influence of the length of treatment on the susceptibility of Candida biofilms to SNs, Candida biofilms (48 h) formed on acrylic specimens were incubated at $37^{\circ} \mathrm{C}(120 \mathrm{rpm})$ with $1 \mathrm{ml}$ of RPMI 1640 medium containing SNs diluted at $54 \mathrm{mg} / \mathrm{l}$ (without temperature and $\mathrm{pH}$ variations) for $5 \mathrm{~h}$ and $24 \mathrm{~h}$. These treatment periods were the same as those used by Harrison et al. [34] to examine the ability of Candida biofilms to survive exposure to various toxic metal ions. After each treatment period (5 h and $24 \mathrm{~h}$ ), acrylic specimens were washed once with $1 \mathrm{ml}$ of PBS to remove nonadherent cells. Controls devoid of SNs were also included.

\section{Quantification of total biofilm biomass}

Total biomass of Candida biofilms exposed to SNs (with or without temperature and $\mathrm{pH}$ variation) was measured using the crystal violet (CV) staining method [5,31]. Briefly, after the treatment period, acrylic specimens were washed once with $1 \mathrm{ml}$ of PBS to remove loosely attached cells. Then, Candida biofilms were fixed with $1 \mathrm{ml}$ of $99 \%$ methanol (Sigma-Aldrich). After $15 \mathrm{~min}$, methanol was removed and the acrylic specimens were allowed to dry at room temperature. Next, $1 \mathrm{ml}$ of CV stain (1\% v/v; Merck KGaA) was added to each well containing acrylic specimens and incubated for $5 \mathrm{~min}$. Acrylic specimens were gently washed with deionized water, dried at room temperature, and transferred to new 24-well microtiter plates. Then, $1 \mathrm{ml}$ of acetic acid $(33 \% \mathrm{v} / \mathrm{v}$; Sigma-Aldrich) was added to remove the $\mathrm{CV}$ stain from the biofilms. Last, absorbance of the obtained solution was measured in a microtiter plate reader (Eon microplate spectrophotometer; BioTek, Winooski, VT, USA) at $570 \mathrm{~nm}$ and standardized in relation to the area of acrylic specimens $\left(\mathrm{Abs} / \mathrm{cm}^{2}\right)$. The assays were performed independently three times in triplicate. 


\section{Quantification of biofilm viable cells}

Cultivable Candida cells from biofilms exposed to SNs (with or without temperature and $\mathrm{pH}$ variation) were enumerated by counting colony-forming units (CFUs). Acrylic specimens were washed once with PBS, immersed in $1 \mathrm{ml}$ of PBS in falcon tubes, sonicated for $30 \mathrm{~s}$ at $40 \mathrm{~W}$, and vortexed for $5 \mathrm{~min}$. Serial decimal dilutions (in PBS) of each biofilm cell suspension were plated on SGA, and the plates were incubated at $37^{\circ} \mathrm{C}$. After $24 \mathrm{~h}$, the total number of colony-forming units per unit area $\left(\log _{10} \mathrm{CFU} / \mathrm{cm}^{2}\right)$ of acrylic specimens was enumerated. The experiments were performed independently three times in triplicate.

\section{Statistical analysis}

The data for each test were analyzed statistically using one-way analysis of variance and the Bonferroni post hoc test, using SPSS software (Statistical Package for the Social Sciences, Inc., Chicago, IL, USA) with significance level denoted at $P<0.05$.

\section{Results}

The absorption spectra for the nonheated SNs (Fig. 1A), SN-50 (Fig. 1B), and SN-70 (Fig. 1C) were similar and demonstrated plasmon bands centered at approximately $430 \mathrm{~nm}$. For SN-100, the absorption peak was attained at approximately $500 \mathrm{~nm}$ (Fig. 1D).

With reference to biofilm biomass quantification, Figure $2 \mathrm{~A}$ shows that preheating of the $\mathrm{SN}$ suspension to $100^{\circ} \mathrm{C}$ impaired its efficacy only for C. albicans 324LA/94. In this case, $\mathrm{SN}-100$ produced a significant increase $(42.9 \%$; $P=0.037)$ in the total biomass compared with the positive control group. The results displayed in Figure 3A indicate that for both strains of C. glabrata, the variation in $\mathrm{pH}$ significantly impaired the efficacy of SNs in reducing total biomass. When the $\mathrm{SN}-\mathrm{pH} 5$ group was compared with the positive control, increases in the total biomass of C. glabrata ATCC 90030 and C. glabrata D1 of $42.9 \%$ $(P=0.036)$ and $25 \%(P=0.045)$, respectively, were observed. In addition, when the $\mathrm{pH}$ was changed to 9.0 , the total biomass increased approximately $38 \%(P=0.036)$ for C. glabrata ATCC 90030 and $39 \%(P=0.009)$ for $C$. glabrata D1 compared with the positive control.

As shown in Figure 4A, C. albicans ATCC 10231, C. albicans 324LA/94, C. glabrata ATCC 90030, and C. glabrata D1 biofilms treated with $\mathrm{SNs}$ for $5 \mathrm{~h}$ showed significant reductions in total biomass of $47.2 \%(P<$ $0.001), 35.8 \%(P<0.001), 51.5 \%(P<0.001)$, and $36.8 \%$ $(P<0.001)$, respectively, compared with their respective controls ( $5 \mathrm{~h}$ without $\mathrm{SN})$. When these biofilms were treated for $24 \mathrm{~h}$, the reductions in the total biomass compared with the control groups were also significant for all strains as follows: C. albicans ATCC 10231: $18.5 \%, P=0.011$; C. albicans 324LA/94: $32.3 \%, P<0.001$; C. glabrata ATCC 90030: $22.3 \%, P=0.001$; and C. glabrata D1: $17.6 \%, P=0.027$. Although the 5 -h treatment resulted in a higher reduction in total biomass than the 24-h treatment, the difference between these treatments was only significant for C. glabrata ATCC $90030(P=0.001)$.

In terms of biofilm cultivable cell quantification, Figures $2 \mathrm{~B}$ and $3 \mathrm{~B}$ clearly show that the temperature and $\mathrm{pH}$ variations neither impaired nor improved significantly the efficacy of SNs against Candida biofilms. On the other hand, the treatments with SNs for $5 \mathrm{~h}$ and $24 \mathrm{~h}$ (Fig. 4B) produced significant decreases in the number of colony-forming units only for C. albicans 324LA/94 (reduction of 1.44- $\log _{10}$; $P<0.001$ ) and C. glabrata D1 (reduction of $0.71-\log _{10}$; $P=0.034)$, respectively, compared with the controls. The comparison between the two treatment periods was statistically significant only for C. albicans 324LA/94 $(P<0.001)$, with better results for the shorter treatment period $(5 \mathrm{~h})$.

\section{Discussion}

There are few reports on how the chemical stability of SNs influences antimicrobial properties. Here, our goal was to determine whether heating or changing the $\mathrm{pH}$ of a $\mathrm{SN}$ stock solution and whether varying the treatment period would affect the antifungal activity of SNs against Candida biofilms. Clinically, SNs could be used in mouthwashes and as a disinfectant solution for soaking dentures. Therefore, in the present study, these nanoparticles were heated to $50^{\circ} \mathrm{C}, 70^{\circ} \mathrm{C}$, and $100^{\circ} \mathrm{C}$. These higher temperatures were used because storage temperatures for colloidal suspensions in some tropical countries and desert regions can exceed $50^{\circ} \mathrm{C}$. Moreover, $100^{\circ} \mathrm{C}$ was chosen to represent an extreme condition and was close to the temperature used to synthesize SNs. Preheating SNs to $50^{\circ} \mathrm{C}, 70^{\circ} \mathrm{C}$, and $100^{\circ} \mathrm{C}$ had no significant influence on total biomass or cell viability of Candida biofilms (Fig. 2). The only exception was the C. albicans 324LA/94 biomass, where SNs heated to $100^{\circ} \mathrm{C}$ induced a $42.9 \%$ increase in total biomass in relation to the no-heated group (positive control). In an attempt to explain these findings, additional tests were performed to verify the behavior of the $\mathrm{SN}$ suspension when subjected to heating.

Aliquots of each SN suspension heated to $50^{\circ} \mathrm{C}, 70^{\circ} \mathrm{C}$, and $100^{\circ} \mathrm{C}$ were evaluated using $\mathrm{UV} / \mathrm{vis}$ spectroscopy (Fig. 1). Surprisingly, SN-50 and SN-70 suspensions did not show extreme changes in their spectral absorption aspects when compared with the nonheated SN suspension, indicating that these suspensions remained stable after $30 \mathrm{~min}$ of heating. This is in agreement with results for total biomass 

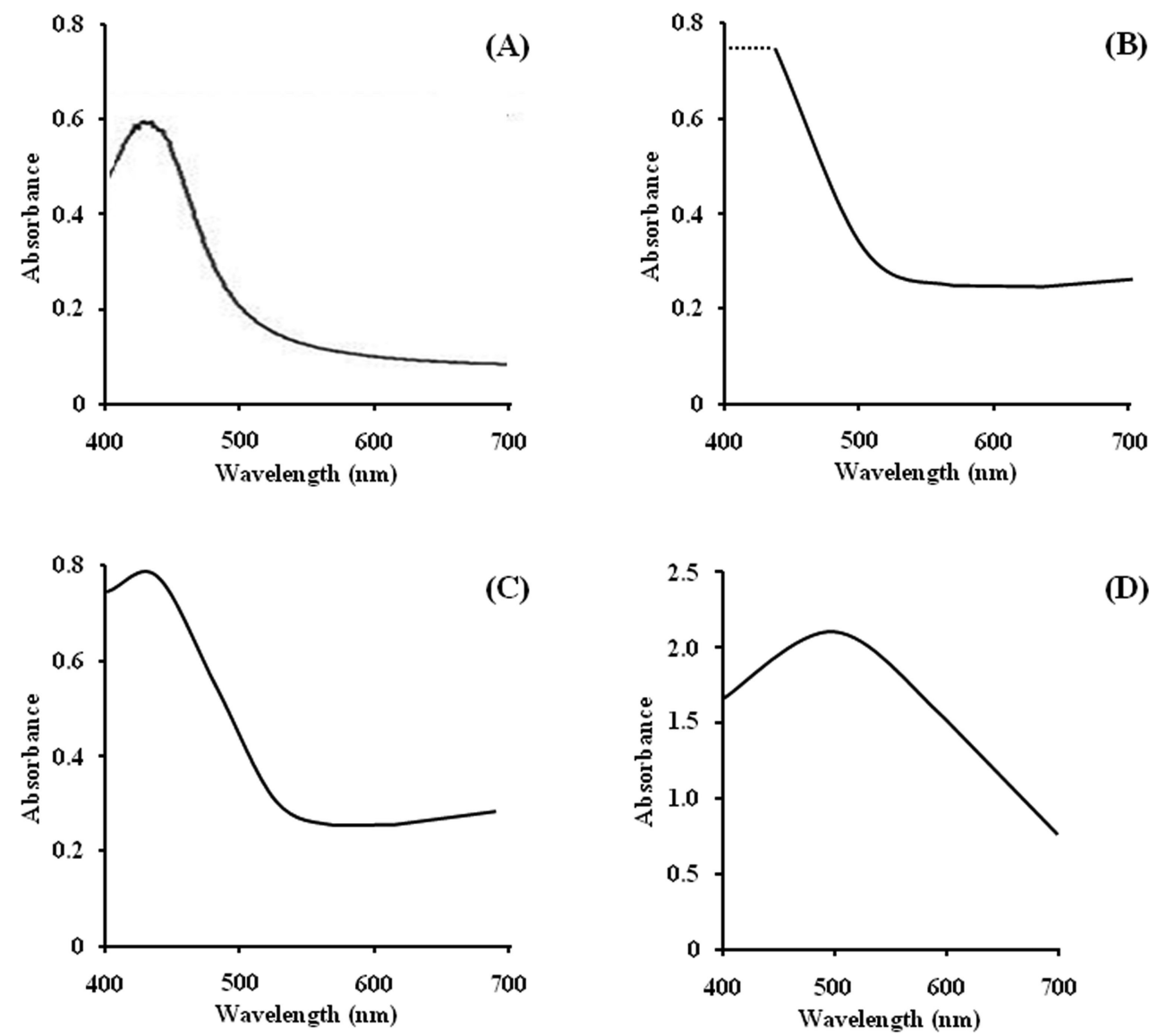

(D)

Figure 1. Ultraviolet/visible spectra of colloidal suspensions of silver nanoparticles not heated (A) and heated to $50^{\circ} \mathrm{C}(\mathrm{B}), 70^{\circ} \mathrm{C}(\mathrm{C})$, and $100^{\circ} \mathrm{C}(\mathrm{D})$.

and cultivable biofilm cells obtained for $\mathrm{SN}-50, \mathrm{SN}-70$, and the control (SN without heating) and explains why there were no significant differences among these groups.

Kittler et al. [29] evaluated the dissolution in water of SNs stabilized with citrate and polyvinylpyrrolidone for up to 125 days at $5^{\circ} \mathrm{C}, 25^{\circ} \mathrm{C}$, and $37^{\circ} \mathrm{C}$. They found that SNs dissolved partially into ions and that an increase in temperature caused an increase in the degree of dissolution and release of SIs. As a result of this process, a considerable increase in the toxicity of SNs was observed. In the present study, although the nanoparticles were heated to high temperatures, the short heating period ( $30 \mathrm{~min}$ ) may have been insufficient to a significantly dissolve these particles and release large amounts of SIs, in turn, improving antibiofilm activity. It must be emphasized that the $\mathrm{SNs}$ used in our study were well stabilized with ammonia. Ammonia's role is to trap all SIs present in the colloidal suspension by forming soluble diamine silver complexes; these complexes prevent the growth of already-formed SNs as well as the formation of new nanoparticles [28].

However, heating the $\mathrm{SN}$ suspension to $100^{\circ} \mathrm{C}$ changed the suspension's color and the particle size distribution. This is shown in Figure 1D by the shift of the absorption peak maximum towards a higher wavelength and the peak broadening of the UV-vis spectra. This might indicate that the $\mathrm{SN}-100$ suspension was significantly destabilized, leading to the formation of silver aggregates or new nanoparticles [35]. However, the efficacy of the $\mathrm{SN}-100$ suspension against Candida biofilms was significantly reduced only for the C. albicans 324LA/94 biomass. Unfortunately, there is no feasible explanation for this finding. These results point to the fact that the storage of colloidal suspension at high temperatures may not compromise the effectiveness of SNs against Candida biofilms. Perhaps, this is due to the inherent tendency for SN agglomeration when in contact with biofilms $[26,36]$.

Regarding the tests performed to evaluate the efficacy of $\mathrm{SN}$ suspensions with a change in $\mathrm{pH}$, it is important to note that $\mathrm{pH} 5.0$ was chosen because it is close to the average $\mathrm{pH}$ of saliva from patients with denture stomatitis [37]; $\mathrm{pH} 9.0$ was arbitrarily chosen as representative of a basic $\mathrm{pH}$. After adjusting the $\mathrm{pH}$ (to 5.0 or 9.0) of $\mathrm{SN}$ colloidal suspensions diluted in RPMI 1640 medium, dark aggregates or flocs settled on the vessel bottom, indicating instability of the colloidal suspensions at both acidic and basic $\mathrm{pH}$. For this reason, UV/vis spectroscopy analysis was not performed. 


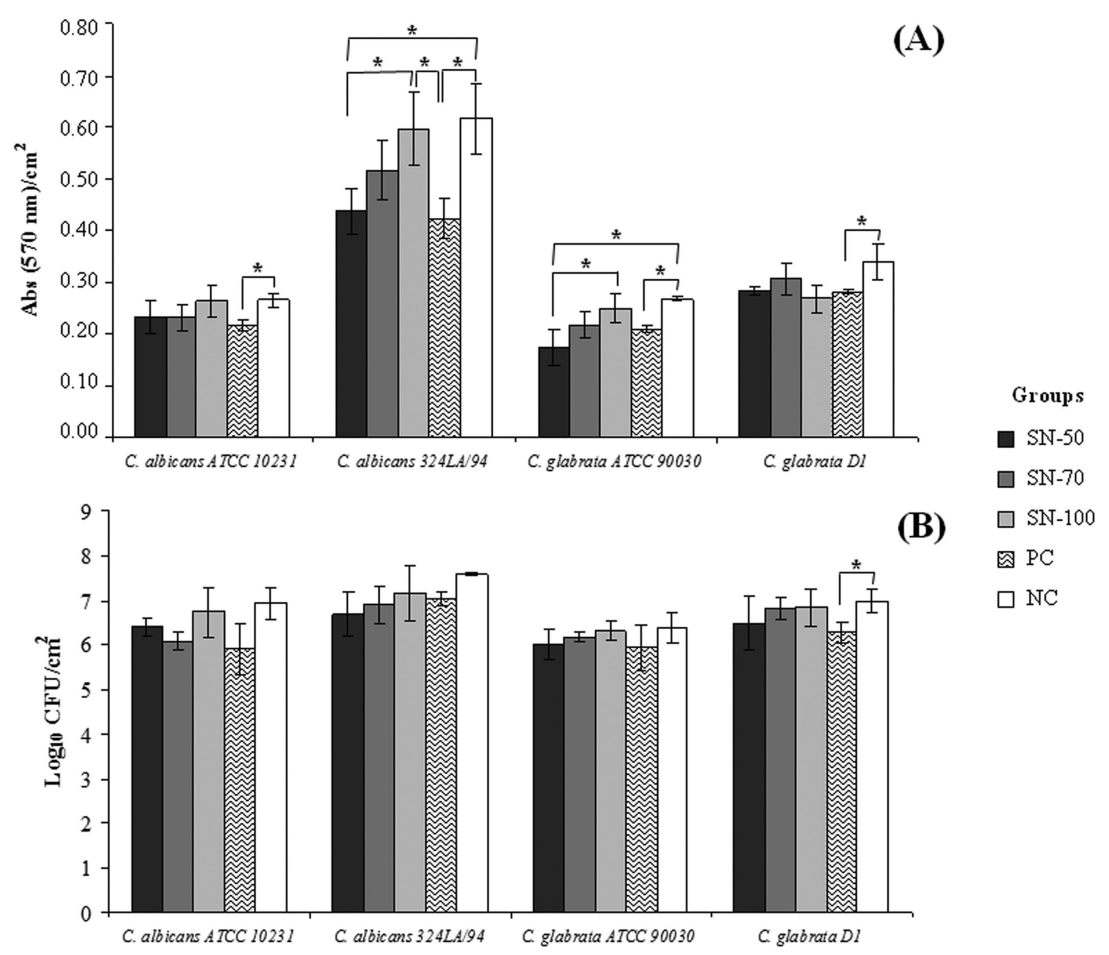

Figure 2. (A) Mean values of the absorbance per square centimeter obtained with crystal violet staining assay and (B) means of the logarithm of colony-forming units per square centimeter for mature Candida biofilms ( $48 \mathrm{~h}$ ) after $24 \mathrm{~h}$ of treatment with silver nanoparticles (SNs) at $54 \mathrm{mg} / \mathrm{L}$ that were preheated to $50^{\circ} \mathrm{C}(\mathrm{SN}-50), 70^{\circ} \mathrm{C}(\mathrm{SN}-70)$, and $100^{\circ} \mathrm{C}(\mathrm{SN}-100)$. Positive control (PC), biofilms incubated with unheated SNs. Negative control (NC), biofilms incubated with Roswell Park Memorial Institute 1640 medium without SNs. Error bars represent standard deviation of the mean. Asterisk $\left({ }^{*}\right)$ denotes $P<0.05$, using analysis of variance followed by the Bonferroni test.

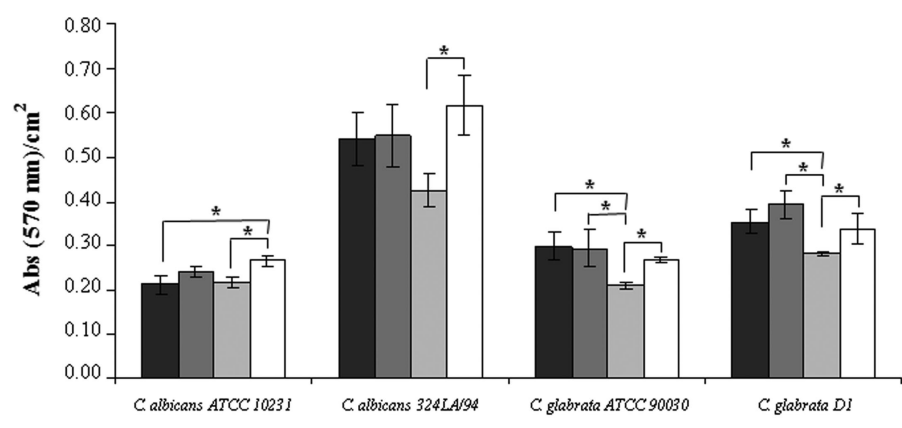

(A)
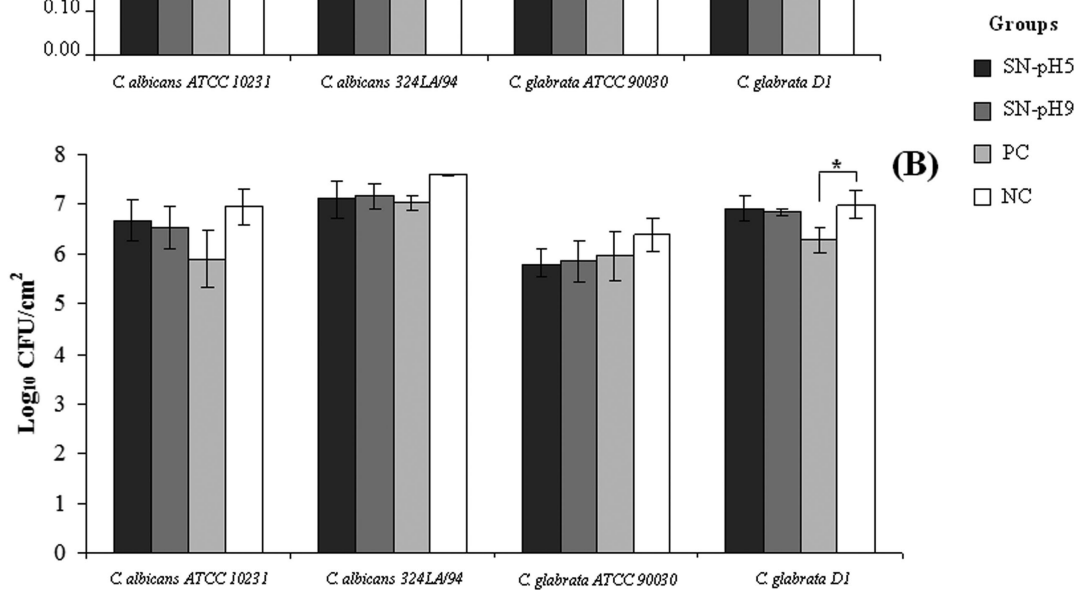

Figure 3. (A) Mean values of the absorbance per square centimeter obtained with crystal violet staining assay and (B) means of the logarithm of colony-forming units per square centimeter for mature Candida biofilms ( $48 \mathrm{~h}$ ) after $24 \mathrm{~h}$ of treatment with silver nanoparticles (SNs) at $54 \mathrm{mg} / \mathrm{L}$ that had the pH varied (during $2 \mathrm{~h}$ ) to $5.0(\mathrm{SN}-\mathrm{pH} 5)$ and $9.0(\mathrm{SN}-\mathrm{pH}$ 9) before contact with biofilms. Positive control (PC), biofilms incubated with SNs without $\mathrm{pH}$ variation. Negative control (NC), biofilms incubated with Roswell Park Memorial Institute 1640 medium without SNs. Error bars represent standard deviation of the mean. Asterisk $(*)$ denotes $P<0.05$, using analysis of variance followed by the Bonferroni test. 


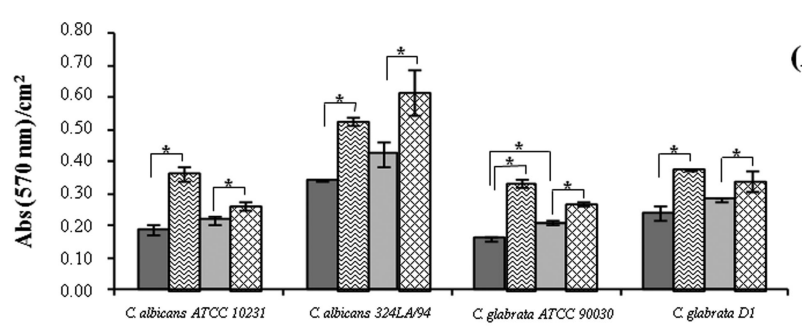

(A)

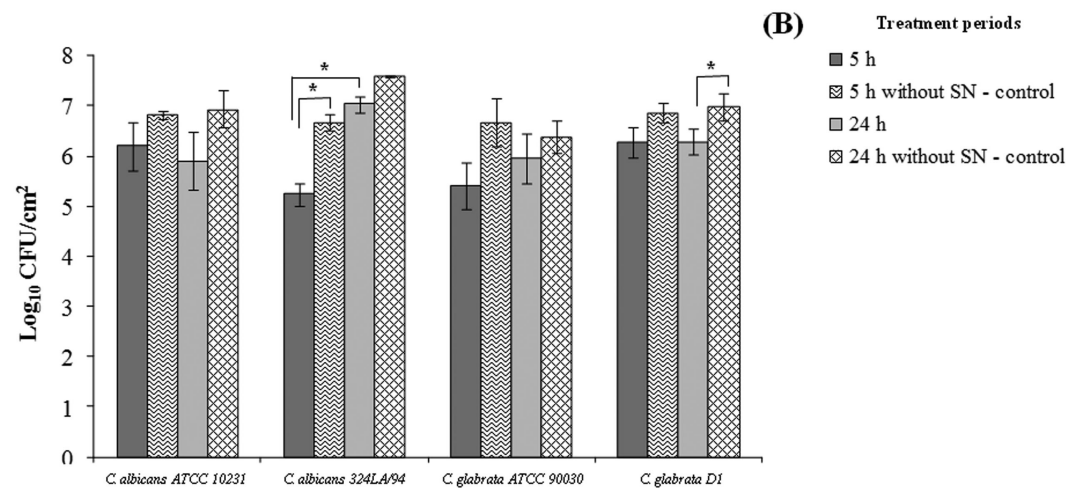

Figure 4. (A) Absorbance values per square centimeter obtained with crystal violet staining assay and (B) means of the logarithm of colony-forming units per square centimeter for mature Candida biofilms ( $48 \mathrm{~h}$ ) after different treatment periods with silver nanoparticles at $54 \mathrm{mg} / \mathrm{L}$. Error bars indicate standard deviation of the mean. Asterisk $\left({ }^{*}\right)$ denotes $P<0.05$, using analysis of variance followed by the Bonferroni test.

According to Kittler et al. [29], the dissolution behavior of nanoparticles in biological medium is definitely more complex and distinct from that in water due to the presence of several organic compounds in the medium. RPMI 1640 medium contains substantial amounts of glucose, amino acids, and proteins. Thus, the addition of hydrochloric acid or sodium hydroxide probably led to a destabilization in the colloidal suspension and favored the release of SIs, which may have bound to proteins or precipitated in the RPMI medium as silver chloride [38], silver phosphate [29], or silver hydroxide.

The results also demonstrate that the variation in $\mathrm{pH}$ did not impair or improve significantly the efficacy of SNs on the number of colony-forming units (Fig. 3B). The reasons for this are related to those mentioned above regarding the effect of temperature stability on the antifungal activity of SNs. However, the $\mathrm{pH}$ changes resulted in significant increases in the total biomass of C. glabrata ATCC 90030 and C. glabrata D1 when compared with the positive controls (Fig. 3A). As C. albicans biofilms are more profuse and produce greater amounts of extracellular matrix than C. glabrata biofilms [7,39], the nanoparticles and some aggregates were likely retained in the matrix and did not reach the cells that were in the deeper layers of the biofilm. If this is the case, it is possible that the contact of aggregates with their cells may have been facilitated in C. glabrata ATCC 90030 and C. glabrata D1 biofilms. Although it did not result in a decrease in the number of viable cells (probably due to SN aggregation), it might have generated a stress response in the biofilm cells; the cells responded by producing more matrix, since the number of viable cells was similar. The lack of correlation between both methods used for biofilm quantification was not surprising, given that the two methods assessed different biofilm features and are accepted as complementary. While CV staining quantified the total biofilm biomass (extracellular matrix and both living and dead cells), the CFU enumeration determined the number of cultivable cells.

Additionally, by comparing the treatment periods ( $5 \mathrm{~h}$ and $24 \mathrm{~h}$ ), there were differences for the biomass of C. glabrata ATCC 90030 biofilm and for the number of colony-forming units of C. albicans 324LA/94 biofilm, with better results for the shorter treatment period for all (Fig. 4). It is likely that the exposure period $(5 \mathrm{~h}$ ) was too short to cause a large aggregation of SNs, in turn, facilitating their antimicrobial action. From a clinical perspective, these results are important because shorter exposures to SNs could prevent the harm that is related to silver toxicity for mammalian cells. What should be considered are the inherent physiological differences among the species and strains tested [39]. For instance, biofilms formed by C. albicans normally have a thin basal yeast layer and a thicker hyphal layer (less compact), whereas C. glabrata biofilms are characterized by a compact monolayer or multilayer of yeasts [39]. These features may hinder or facilitate the action of SN against C. albicans and C. glabrata biofilms.

Based on the results of our study, the use of stabilized or destabilized SNs may not be crucial to how SNs affect 
against Candida biofilms. Additional research to elucidate the longevity of SN formulation, especially under oral temperature and $\mathrm{pH}$ conditions, is needed. In addition, research on the toxicological effects that result when nanoparticles are changed by environmental variations is needed. Moreover, studies on the incorporation of SNs into acrylic resin and on the physical, mechanical, and microbiological properties of the nanocomposites generated are also necessary in order to develop biomaterials that will prevent or control Candida-associated denture stomatitis.

In summary, the results indicate that temperature and $\mathrm{pH}$ variations of SNs did not affect their efficacy against the sessile cells of Candida biofilms. Furthermore, the treatment periods were not decisive in terms of the susceptibility to $\mathrm{SNs}$, and the shorter treatment period might be clinically advantageous. Accordingly, these results provide important insights that could be useful in the treatment of Candidaassociated denture stomatitis with formulations and biomaterials containing SNs.

\section{Acknowledgments}

We thank Dr David Williams, Cardiff University, Cardiff, UK, for providing the strain 324LA/94. The authors also thank São Paulo Research Foundation (FAPESP, process 2009/15146-5), Brazil, for supporting the work of D. R. M. The authors are indebted to Laboratório Interdisciplinar de Eletroquímica e Cerâmica, Federal University of São Carlos, Brazil, in the name of Andressa Kubo, for preparing and characterizing the colloidal suspensions of silver nanoparticles.

\section{Declaration of interest}

The authors report no conflicts of interest. The authors alone are responsible for the content and the writing of the paper.

\section{References}

1. Chandra J, Mukherjee PK, Leidich SD et al. Antifungal resistance of candidal biofilms formed on denture acrylic in vitro. J Dent Res 2001; 80: 903-908.

2. Al-Dwairi ZN. Prevalence and risk factors associated with denture-related stomatitis in healthy subjects attending a dental teaching hospital in North Jordan. J Ir Dent Assoc 2008; 54: 80-83.

3. Coco BJ, Bagg J, Cross LJ et al. Mixed Candida albicans and Candida glabrata populations associated with the pathogenesis of denture stomatitis. Oral Microbiol Immunol 2008; 23: 377383.

4. Vanden Abbeele A, de Meel H, Ahariz M et al. Denture contamination by yeasts in the elderly. Gerodontology 2008; 25: 222-228.

5. Silva S, Pires P, Monteiro DR et al. The effect of silver nanoparticles and nystatin on mixed biofilms of Candida glabrata and Candida albicans on acrylic. Med Mycol 2013; 51: 178-184.
6. Redding S, Bhatt B, Rawls HR et al. Inhibition of Candida albicans biofilm formation on denture material. Oral Surg Oral Med Oral Pathol Oral Radiol Endod 2009; 107: 669-672.

7. Silva S, Negri M, Henriques M et al. Candida glabrata, Candida parapsilosis and Candida tropicalis: biology, epidemiology, pathogenicity and antifungal resistance. FEMS Microbiol Rev 2012; 36: 288-305.

8. Vandenbosch D, Braeckmans K, Nelis HJ, Coenye T. Fungicidal activity of miconazole against Candida spp. biofilms. J Antimicrob Chemother 2010; 65: 694-700.

9. Salerno C, Pascale M, Contaldo M et al. Candida-associated denture stomatitis. Med Oral Patol Oral Cir Bucal 2011; 16: e139-143.

10. Hawser SP, Douglas LJ. Resistance of Candida albicans biofilms to antifungal agents in vitro. Antimicrob Agents Chemother 1995; 39: 2128-2131.

11. Chandra J, Kuhn DM, Mukherjee PK et al. Biofilm formation by the fungal pathogen Candida albicans: development, architecture, and drug resistance. J Bacteriol 2001; 183: 53855394.

12. Watamoto T, Samaranayake LP, Jayatilake JA et al. Effect of filamentation and mode of growth on antifungal susceptibility of Candida albicans. Int J Antimicrob Agents 2009; 34: $333-$ 339.

13. Tobudic S, Kratzer C, Lassnigg A, Graninger W, Presterl E. In vitro activity of antifungal combinations against Candida albicans biofilms. J Antimicrob Chemother 2010; 65: 271-274.

14. Monteiro DR, Silva S, Negri M et al. Silver nanoparticles: influence of stabilizing agent and diameter on antifungal activity against Candida albicans and Candida glabrata biofilms. Lett Appl Microbiol 2012; 54: 383-391.

15. Rai M, Yadav A, Gade A. Silver nanoparticles as a new generation of antimicrobials. Biotechnol Adv 2009; 27: 76-83.

16. Monteiro DR, Gorup LF, Takamiya AS et al. The growing importance of materials that prevent microbial adhesion: antimicrobial effect of medical devices containing silver. Int J Antimicrob Agents 2009; 34: 103-110.

17. Ahn SJ, Lee SJ, Kook JK, Lim BS. Experimental antimicrobial orthodontic adhesives using nanofillers and silver nanoparticles. Dent Mater 2009; 25: 206-213.

18. Zhang K, Melo MA, Cheng L et al. Effect of quaternary ammonium and silver nanoparticle-containing adhesives on dentin bond strength and dental plaque microcosm biofilms. Dent Mater 2012; 28: 842-852.

19. Cheng L, Weir MD, Xu HH et al. Antibacterial amorphous calcium phosphate nanocomposites with a quaternary ammonium dimethacrylate and silver nanoparticles. Dent Mater 2012; 28: 561-572.

20. Monteiro DR, Gorup LF, Takamiya AS et al. Silver distribution and release from an antimicrobial denture base resin containing silver colloidal nanoparticles. J Prosthodont 2012; 21: 7-15.

21. Lok CN, Ho CM, Chen R et al. Proteomic analysis of the mode of antibacterial action of silver nanoparticles. J Proteome Res 2006; 5: 916-924.

22. Lok CN, Ho CM, Chen R et al. Silver nanoparticles: partial oxidation and antibacterial activities. J Biol Inorg Chem 2007; 12: $527-534$. 
23. Costa CS, Ronconi JV, Daufenbach JF et al. In vitro effects of silver nanoparticles on the mitochondrial respiratory chain. Mol Cell Biochem 2010; 342: 51-56.

24. Dibrov P, Dzioba J, Gosink KK, Häse CC. Chemiosmotic mechanism of antimicrobial activity of $\mathrm{Ag}^{+}$in $\mathrm{Vib}-$ rio cholerae. Antimicrob Agents Chemother 2002; 46: 26682670.

25. Kim KJ, Sung WS, Suh BK et al. Antifungal activity and mode of action of silver nano-particles on Candida albicans. Biometals 2009; 22: 235-242.

26. Monteiro DR, Silva S, Negri M et al. Silver colloidal nanoparticles: effect on matrix composition and structure of Candida albicans and Candida glabrata biofilms. J Appl Microbiol 2013; 114: $1175-1183$.

27. Monteiro DR, Silva S, Negri M et al. Antifungal activity of silver nanoparticles in combination with nystatin and chlorhexidine digluconate against Candida albicans and Candida glabrata biofilms. Mycoses 2013; 56: 672-680.

28. Gorup LF, Longo E, Leite ER, Camargo ER. Moderating effect of ammonia on particle growth and stability of quasi-monodisperse silver nanoparticles synthesized by the Turkevich method. J Colloid Interface Sci 2011; 360: 355-358.

29. Kittler S, Greulich C, Diendorf J, Köller M, Epple M. Toxicity of silver nanoparticles increases during storage because of slow dissolution under release of silver ions. Chem Mater 2010; 22: 4548-4554.

30. Adegboyega NF, Sharma VK, Siskova K et al. Interactions of aqueous $\mathrm{Ag}+$ with fulvic acids: mechanisms of silver nanoparticle formation and investigation of stability. Environ Sci Technol 2013; 47: 757-764.
31. Monteiro DR, Gorup LF, Silva S et al. Silver colloidal nanoparticles: antifungal effect against Candida albicans and Candida glabrata adhered cells and biofilms. Biofouling 2011; 27: 711719.

32. Ellis D, Gosai J, Emrick C et al. Occidiofungin's chemical stability and in vitro potency against Candida species. Antimicrob Agents Chemother 2012; 56: 765-769.

33. Lamfon H, Porter SR, McCullough M, Pratten J. Formation of Candida albicans biofilms on non-shedding oral surfaces. Eur J Oral Sci 2003; 111: 465-471.

34. Harrison JJ, Rabiei M, Turner RJ et al. Metal resistance in Candida biofilms. FEMS Microbiol Ecol 2006; 55: 479-491.

35. Delay M, Dolt T, Woellhaf A, Sembritzki R, Frimmel FH. Interactions and stability of silver nanoparticles in the aqueous phase: Influence of natural organic matter (NOM) and ionic strength. J Chromatogr A 2011; 1218: 4206-4212.

36. Choi O, Yu CP, Esteban Fernández G, Hu Z. Interactions of nanosilver with Escherichia coli cells in planktonic and biofilm cultures. Water Res 2010; 44: 6095-6103.

37. Baena-Monroy T, Moreno-Maldonado V, Franco-Martínez F et al. Candida albicans, Staphylococcus aureus and Streptococcus mutans colonization in patients wearing dental prosthesis. Med Oral Patol Oral Cir Bucal 2005; 10: E27-E39.

38. El Badawy AM, Luxton TP, Silva RG et al. Impact of environmental conditions ( $\mathrm{pH}$, ionic strength, and electrolyte type) on the surface charge and aggregation of silver nanoparticles suspensions. Environ Sci Technol 2010; 44: 1260-1266.

39. Silva S, Negri M, Henriques M et al. Adherence and biofilm formation of non-Candida albicans Candida species. Trends Microbiol 2011; 19: 241-247. 